\title{
Secondary organic aerosol formation from primary aliphatic amines with $\mathrm{NO}_{3}$ radical
}

\author{
Q. G. J. Malloy ${ }^{1,2}$, Li Qi ${ }^{1,2}$, B. Warren ${ }^{1,2}$, D. R. Cocker III ${ }^{1,2}$, M. E. Erupe ${ }^{3, *}$, and P. J. Silva ${ }^{3, * *}$ \\ ${ }^{1}$ University of California-Riverside, Bourns College of Engineering, Department of Chemical and Environmental \\ Engineering, Riverside, CA 92521-0001, USA \\ ${ }^{2}$ Bourns College of Engineering-Center for Environmental Research and Technology (CE-CERT), Riverside, CA, USA \\ ${ }^{3}$ Department of Chemistry and Biochemistry, Utah State University, 0300 Old Main Hall, Logan, UT 84322-0300, USA \\ *now at: Kent State University, Department of Chemistry, Kent, OH 44242, USA \\ ** now at: United States Department of Agriculture, USDA-ARS, 230 Bennett Lane, Bowling Green, KY 42104, USA
}

Received: 7 May 2008 - Published in Atmos. Chem. Phys. Discuss.: 4 July 2008

Revised: 6 November 2008 - Accepted: 27 February 2009 - Published: 23 March 2009

\begin{abstract}
Primary aliphatic amines are an important class of nitrogen containing compounds emitted from automobiles, waste treatment facilities and agricultural animal operations. A series of experiments conducted at the UC-Riverside/CECERT Environmental Chamber is presented in which oxidation of methylamine, ethylamine, propylamine, and butylamine with $\mathrm{O}_{3}$ and $\mathrm{NO}_{3}$ have been investigated. Very little aerosol formation is observed in the presence of $\mathrm{O}_{3}$ only. However, after addition of $\mathrm{NO}$, and by extension $\mathrm{NO}_{3}$, large aerosol mass yields ( $\sim 4 \%$ for butylamine) are seen. Aerosol generated was determined to be organic in nature due to the small fraction of $\mathrm{NO}$ and $\mathrm{NO}_{2}$ in the total signal $(<1 \%$ for all amines tested) as detected by an aerosol mass spectrometer (AMS). We propose a reaction mechanism between carbonyl containing species and the parent amine leading to formation of particulate imine products. These findings can have significant impacts on rural communities with elevated nighttime PM loadings, when significant levels of $\mathrm{NO}_{3}$ exist.
\end{abstract}

\section{Introduction}

Amines are found to be emitted into the atmosphere by a variety of anthropogenic and biogenic sources including automobile emissions, waste treatment facilities, and agricultural animal operations (Westerholm et al., 1993; Manahan, 1990; Schade and Crutzen, 1995). Amine emission rates from dairy operations have been estimated to range from 0.2 to $11 \mathrm{lbs}$ per head of cattle per year (Bailey et al., 2005). Additionally, Mosier et al. (1973) has identified cattle feedlots as a

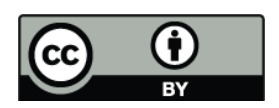

Correspondence to: P. J. Silva

(phil.silva@ars.usda.gov) major source of methylamine, ethylamine, propylamine, and butylamine as well as other amine compounds.

Removal routes for amines from the atmosphere include reactions with either nitric or sulfuric acid to form the corresponding nitrate salts or oxidation by $\mathrm{OH}, \mathrm{O}_{3}$, and $\mathrm{NO}_{3}$ (Seinfeld and Pandis, 1998; Finlayson-Pitts and Pitts, 2000; Silva et al., 2008). Little work has been performed on the $\mathrm{NO}_{3}$ initiated oxidation of amines however; it is thought to be similar to the $\mathrm{OH}$ route and therefore proceed by four possible reaction pathways. The predominant pathway (Fig. 1) is through abstraction of the alpha hydrogen, which forms the alkoxy radical after addition of molecular oxygen and $\mathrm{NO}$ to $\mathrm{NO}_{2}$ conversion or $\mathrm{RO}_{2}-\mathrm{RO}_{2}$ reactions in the absence of NO. The alkoxy radical then proceeds to form an amide. The second route proceeds by loss of an alkyl group from the nitrogen, followed by formation of nitramine, nitrosamine, or imines. Imines' are then believed to undergo reactions leading to formation of aldehyde products. It is possible for these oxidation products to have a low enough vapor pressure to condense onto existing particles or form new particles by nucleating, creating secondary organic aerosol (SOA). Once in the aerosol, they can undergo further reactions forming multifunctional species (Pitts et al., 1978).

The presence of organic nitrogen in the particle phase has been reported as far back as the early 1970's when Novakov et al. (1972) found nitrogen with oxidation states similar to that of organic nitrogen compounds in aerosol collected in Pasadena, California. More recently, studies have reported the presence of amine like compounds in ambient particles in both urban and rural settings (Murphy and Thomson, 1997; Angelino et al., 2001; Tan et al., 2002; Glagolenko and Phares, 2004; Beddows et al., 2004). Furthermore, amine like compounds have also been reported in fog water and rain drops obtained in the central valley of

Published by Copernicus Publications on behalf of the European Geosciences Union. 


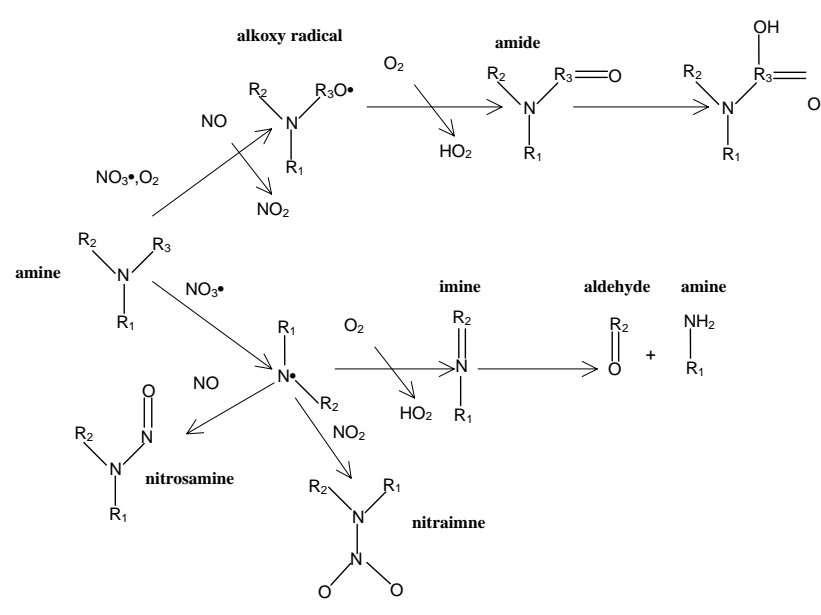

Fig. 1. Proposed reaction scheme of amine oxidation adapted from Schade et al. (1995) to show oxidation by $\mathrm{NO}_{3}$.

California by Zhang and Anastasio (2003). In addition to these studies, recent work by Barsanti et al. (2008) and Smith et al. (2008) have correlated new particle events with elevated amine concentrations. These researchers suggest that amine compounds participate in these nucleation events, possibly acting as cloud condensation nuclei (Barsanti et al., 2008; Smith et al., 2008).

Recent work has attempted to shed light on the processes that lead to the presence of amines in the aerosol-phase through mass spectrometry studies of aerosol generated in smog chambers. These studies have shown that most particles generated from amines are in the form of alkyl nitrate salts (Angelino et al., 2001). The exception to this has been tertiary amines, where Murphy et al. (2007) determined secondary organic aerosol formation mass yields of 5-23\% (Murphy et al., 2007). More recently, Silva et al. (2008) observed increases in amine ions from nighttime ambient aerosol sampling (Silva et al., 2008). He estimated that amine containing particles account for $0.5-6 \mu \mathrm{g} / \mathrm{m}^{3}$ of the ultrafine aerosol in Logan, Utah. Subsequently, laboratory investigations of trimethylamine (TMA) with $\mathrm{NO}_{3}$ revealed the presence of highly oxidized large molecular weight ions indicating that $\mathrm{NO}_{3}$ can play a significant role in the nighttime chemistry of TMA with estimated gas-to-particle conversions of $65 \%$. Therefore, this paper investigates secondary particle formation from other commonly emitted primary amines.

\section{Experimental}

All experiments were conducted at the UCR/CE-CERT Environmental Chamber, which has been described in detail elsewhere (Carter et al., 2005). In short, this facility consists of two $90 \mathrm{~m}^{3}$ Teflon reactors attached to a rigid collapsible frame, which are maintained at a slight positive pressure to minimize diffusion of any contaminate into the reactors. The reactors are located in a temperature controlled room, which is continually flushed with pure air. Connected to the reactors are a suite of instrumentation including an Aerodyne high resolution time of flight mass spectrometer (HRToF-AMS), and two scanning mobility particle spectrometers (SMPS), built in house, capable of sizing particles from 28-730 nm (Wang and Flagan, 1990). Particle number and volume were wall loss corrected using the method of Bowman et al. (1997), additionally, particle mass loadings were calculated assuming a unit density (Bowman et al., 1997). Ports into the chamber enable introduction of compounds of interest as well as monitoring of $\mathrm{NO}_{\mathrm{x}}$ using a Thermal Environmental Instruments model $42 \mathrm{C}$ chemiluminescent analyzer and $\mathrm{O}_{3}$ by a Dasibi Environemtal Corp 1003-AH. Initial concentrations of $\mathrm{NO}_{\mathrm{x}}$ and $\mathrm{O}_{3}$ were below the detection limits of our analyzers (50 ppt and $2 \mathrm{ppb}$, respectively) for each experiment performed. PTRMS measurements of the parent amine were also attempted; however, no measureable ion signals were detected for the parent amine compounds.

Amines (Sigma Aldrich, purity $\geq 99 \%$ ) were introduced into a dark chamber by injecting a known volume of liquid amine into a small glass injection manifold or by introducing a known volume of the gas phase amine into a calibrated bulb based on calculated partial pressures. Pure nitrogen was then passed over the liquid or through the bulb, flushing the amine into the reactors. Table 1 lists the experimental conditions of all experiments conducted. $350-400 \mathrm{ppb}$ of ozone was introduced by passing 35 psi of pure air through two UV ozone generators only after the mass concentration of particles formed from initial injection of the parent amine had reached a steady state $(\sim 2 \mathrm{~h})$. $\mathrm{NO}_{\mathrm{x}}$ was added to the reactors as NO using a calibrated bulb approximately $2 \mathrm{~h}$ after ozone addition, when aerosol mass concentrations had once again reached a steady value. Total aerosol yields $(Y)$ were determined using the aerosol yield equation as defined by Odum et al. (1996) with slight modification.

$Y=\frac{\Delta M}{\Delta \mathrm{ROG}}$

where $\Delta M\left(\mu \mathrm{g} / \mathrm{m}^{3}\right)$ is the total aerosol mass concentration produced for a given amount of reactive organic gas reacted ( $\Delta \mathrm{ROG}, \mu \mathrm{g} / \mathrm{m}^{3}$ ) (Odum et al., 1996). This definition differs from the more traditional form of the yield equation in that it accounts for the fact that all aerosol produced might not be organic in nature

Sampling of aerosol for off-line analysis was performed by drawing air for $3 \mathrm{~h}$ at 25 LPM from the reactors through a stainless steel sampling port located just below the chamber onto pre-baked quartz fiber filters (Pall Life Sciences Laboratory). Filters were then extracted by sonication for $30 \mathrm{~min}$ with $5 \mathrm{ml}$ of HPLC grade water (Fisher Scientific Optima Grade). During the sonication period, the extracts were kept cold to minimize liquid phase reactions and losses due to volatilization. Extracts were then filtered through 
Table 1. List of experiments performed and concentrations of reactants.

\begin{tabular}{ccccc}
\hline Experiment & Amine & $\begin{array}{c}\text { Estimated Initial Amine } \\
\text { Concentration }(\mathrm{ppb})\end{array}$ & $\begin{array}{c}\text { Ozone Concentration } \\
(\mathrm{ppb})\end{array}$ & $\begin{array}{c}\mathrm{NO}_{\mathrm{x}} \text { Concentration } \\
(\mathrm{ppb})\end{array}$ \\
\hline 831 & Butylamine & 100 & 352 & 39 \\
833 & Propylamine & 100 & 328 & 61 \\
834 & Methylamine & 100 & 350 & 34 \\
842 & Ethylamine & 100 & 400 & 25 \\
\hline
\end{tabular}

a $1 \mu \mathrm{m}$ pore size syringe filter (Whatman) to remove any quartz fibers and concentrated to $1 \mathrm{ml}$ under a stream of pure nitrogen before analysis.

\subsection{High Pressure Liquid Chromatograph - Time Of Flight} Mass Spectrometer (HPLC-TOF)

The HPLC-TOF (Agilent Technologies, model 6210) was operated in positive ionization mode with an atmospheric pressure chemical ionization source with a gas temperature of $300^{\circ} \mathrm{C}$, vaporizer temperature of $250^{\circ} \mathrm{C}$, corona current of $4 \mu \mathrm{A}$, drying gas flow of $5 \mathrm{~L} \mathrm{~min}^{-1}$ and a nebulizer pressure of 40 psig. Ultra pure nitrogen was used as the carrier gas. Samples were injected using a flow injection process with HPLC grade water along with two mass reference compounds to ensure a mass accuracy of $5 \mathrm{ppm}$ or greater. No acidic modifier was used in the mobile phase to prevent acidbase reactions during analysis. Analytical standards for identified products were not commercial available.

\subsection{High Resolution Time of Flight Aerosol Mass Spec- trometer (AMS)}

Details of this instrument and data analysis methods have been explained in detail by DeCarlo et al. (2006). In brief, the instrument samples through an aerodynamic lens into a time-of-flight chamber; particles between $50-600 \mathrm{~nm}$ are transmitted with $100 \%$ efficiency. In the time-of-flight chamber particles are accelerated until impacting on to a tungsten heater maintained at $600^{\circ} \mathrm{C}$, at which point the nonrefractory aerosol vaporizes and is subjected to electron impact ionization at $70 \mathrm{eV}$.

Ions are guided using a series of lenses to the orthogonal extractor, where they are pulsed into the time-of-flight chamber approximately every $13 \mu \mathrm{s}$. Depending on the mode of operation ions are either reflected towards a mirco-channel plate (MCP) detector following a standard reflectron timeof-flight configuration ( $\mathrm{V}$-mode), or ions leaving the reflector are directed first to a hard mirror then back towards the reflector then finally to the $\mathrm{MCP}$ (W-mode), more than doubling the path length of V-mode operation and increasing $\mathrm{m} / \mathrm{z}$ resolution.

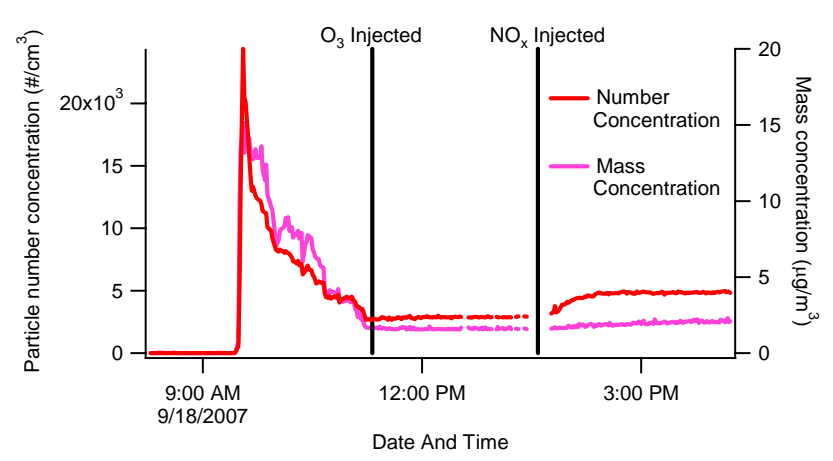

Fig. 2. Wall loss corrected aerosol mass and number evolution for methylamine/ $\mathrm{NO}_{3}$ reaction showing little organic aerosol formation after addition of $\mathrm{NO}_{\mathrm{x}}$.

\section{Results and discussion}

\subsection{Methylamine}

Particle formation was observed immediately after injection of methylamine into the clean reactors (Fig. 2). These particles result from the formation of methylaminium nitrate produced by reaction of methylamine with trace amounts of $\mathrm{NO}_{\mathrm{x}}$ present in the chamber (see Sect. 4.1 for discussion of this salt formation). Addition of ozone had no effect on the particle number or volume. However, a rapid increase in particle number and volume was observed after addition of $\mathrm{NO}_{3}$ (as $\mathrm{O}_{3}+\mathrm{NO}_{\mathrm{x}}$ ) to the chamber; ultimately producing $<2 \mu \mathrm{g} / \mathrm{m}^{3}$ of aerosol after wall loss correction. Assuming total consumption of methylamine, an aerosol mass yield of 1.6\% was determined using Eq. (1).

Particle composition (Fig. 3) measured by the AMS in $\mathrm{W}$-mode after addition of $\mathrm{NO}_{\mathrm{x}}$ to the system clearly shows the fragments of $m / z 30\left(\mathrm{CH}_{4} \mathrm{~N}^{+}\right), m / z 41\left(\mathrm{C}_{3} \mathrm{H}_{5}^{+}\right), m / z 42$ $\left(\mathrm{C}_{2} \mathrm{H}_{4} \mathrm{~N}^{+}\right)$, and a small signal from ion $m / z 46\left(\mathrm{NO}_{2}^{+}\right)$. Proposed structures of these ions are shown in Fig. 4. Off-line filter analysis was not performed due to the lack of mass formed during this experiment. 


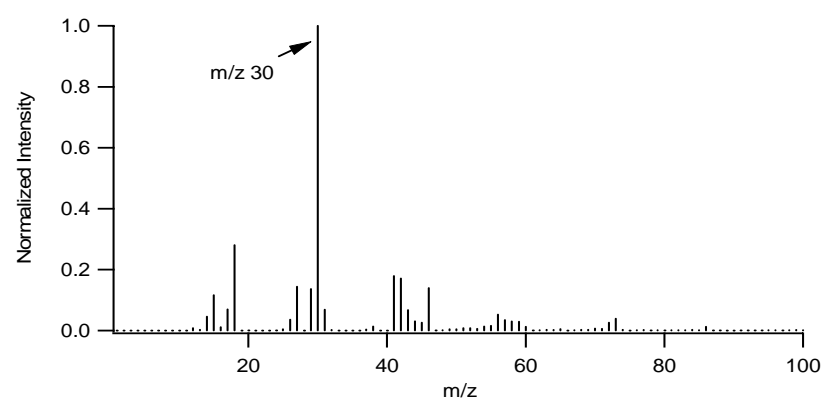

Fig. 3. Background subtracted AMS spectrum normalized to $m / z 30$ from the methylamine/ $\mathrm{NO}_{3}$ system showing no mass fragments other than those of the parent amine.

\section{AMS ions}

\begin{tabular}{|c|c|}
\hline 30.035 & $\mathrm{H}_{2} \mathrm{~N}-\stackrel{\oplus}{\mathrm{C}} \mathrm{H}_{2}$ \\
\hline 41.037 & \\
\hline 42.035 & \\
\hline
\end{tabular}

Fig. 4. Proposed structures of $\mathrm{AMS}$ ions for Methylamine/ $\mathrm{NO}_{3}$ system.

\subsection{Ethylamine}

Particle formation is seen immediately after injection of ethylamine to the reactors (Fig. 5). These particles are from aminium nitrate salt formed from reactions between the amine and trace amounts of $\mathrm{NO}_{\mathrm{x}}$ in the chamber, similar to the methylamine system. Addition of ozone to the system had no measureable effect on particle number or mass. However, in contrast to methylamine, particle formation increased at a rapid rate once $\mathrm{NO}_{3}$ was introduced to the chamber (as $\mathrm{O}_{3}+\mathrm{NO}$ ), ultimately producing $\sim 80 \mu \mathrm{g} / \mathrm{m}^{3}$ (mass yield $\sim 44 \%$ ).

The mass spectrum as detected by the AMS (Fig. 6) shows the $m / z$ fragments appear similar to that of methylamine despite the dramatic differences in aerosol formed, with the exception of the appearance of $m / z 44\left(\mathrm{C}_{2} \mathrm{H}_{6} \mathrm{~N}^{+}\right)$. W-mode data indicates the appearance of a high mass fragments at $\mathrm{m} / z 59.035$ and 100.06 , which can be attributed to $\mathrm{C}_{2} \mathrm{H}_{5} \mathrm{NO}^{+}$ and $\mathrm{C}_{4} \mathrm{H}_{8} \mathrm{~N}_{2} \mathrm{O}^{+}$respectively and which might account for the differences in aerosol formation between the methylamine system and this system.

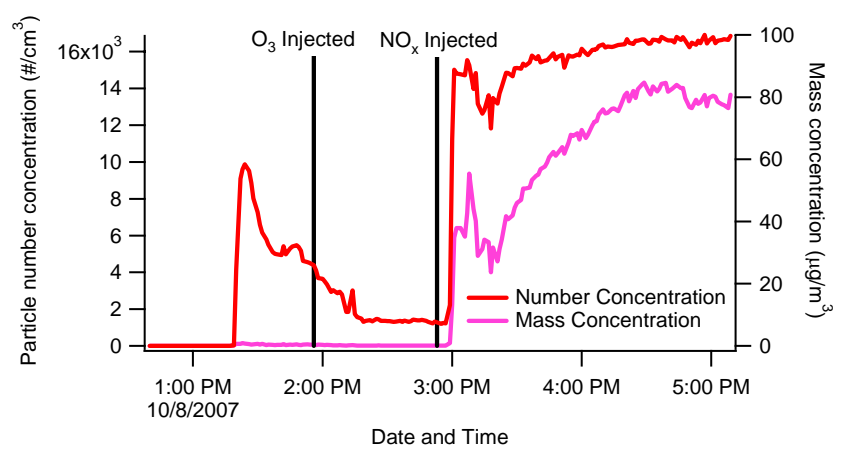

Fig. 5. Wall loss corrected aerosol mass and number evolution for ethylamine/ $\mathrm{NO}_{3}$ reaction indicating a rapid and large increase in organic aerosol formation after addition of $\mathrm{NO}_{\mathrm{x}}$.
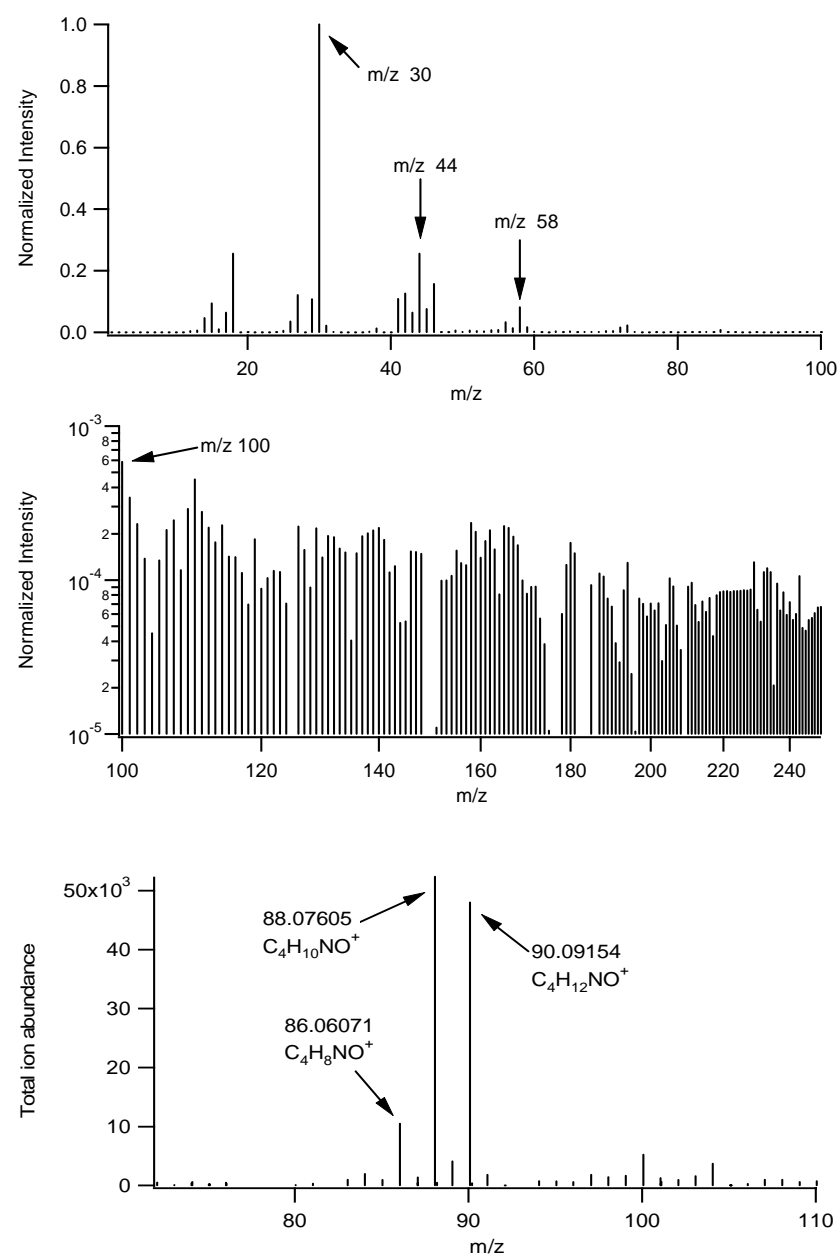

Fig. 6. Frames 1 and 2: AMS mass spectra normalized to $m / z 30$ of the ethylamine/ $\mathrm{NO}_{3}$ system indicating the important peaks. Frame 3: HPLC-TOF filter spectrum of ethylamine/ $\mathrm{NO}_{3}$ indicating formation of imines and their stable intermediates. 


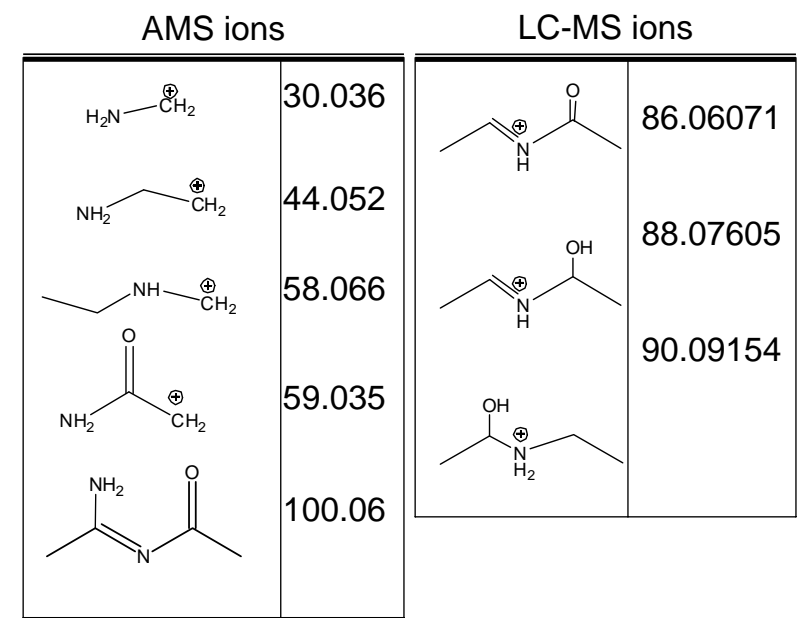

Fig. 7. Proposed structure of AMS and LC-MS ions for Ethylamine/ $\mathrm{NO}_{3}$ system.

Filter analysis (Fig. 6) indicates the presence of ions at $\mathrm{m} / \mathrm{z}^{\prime} \mathrm{s}$ of 88.07605 and 90.09154 which have been identified as a hydroxyl containing imine $\left(\mathrm{C}_{4} \mathrm{H}_{10} \mathrm{NO}^{+}\right)$and the stable carbinolamine $\left(\mathrm{C}_{4} \mathrm{H}_{12} \mathrm{NO}^{+}\right)$, respectively. Figure 7 lists the major ions and proposed structure associated with them. Water was used as the sole extraction solvent to efficiently remove nitrate salts from the filter, which were originally thought to dominate the aerosol phase species by their formation through acid-base chemistry. Clearly this was not the case; therefore, the possibility exists that hydrophobic compounds remained on the filter during extraction that were not detected by HPLC-TOF analysis.

\subsection{Propylamine}

Similar to the two previously studied amines, an initial nucleation burst of aminium nitrate salt was apparent immediately after injection of the amine followed by the rapid decay in particle number and volume (Fig. 8). A second rapid burst of particle formation was observed after addition of $\mathrm{NO}_{3}$ (as $\mathrm{O}_{3}+\mathrm{NO}_{\mathrm{x}}$ ) to the chamber; similar to the initial burst it was followed by decay of the particle volume indicating possible formation and evaporation of salts. However, the particle mass loading eventually stabilized around $53 \mu \mathrm{g} / \mathrm{m}^{3}$ (yield of $22 \%$ ). Very little $\mathrm{NO}^{+}$or $\mathrm{NO}_{2}^{+}$signal was apparent in the high resolution HR-ToF-AMS data, indicating that a large portion of the condensable species formed by the addition of $\mathrm{NO}_{\mathrm{x}}$ to the chamber were not nitrate salts.

The spectrum obtained by the AMS (Fig. 9) is markedly different from that of methylamine and ethylamine showing prominent mass fragments upwards of $m / z 146$. Using the $\mathrm{W}$-mode of the AMS, these fragments can be attributed to $100.07\left(\mathrm{C}_{5} \mathrm{H}_{10} \mathrm{NO}^{+}\right), 100.11\left(\mathrm{C}_{6} \mathrm{H}_{14} \mathrm{~N}^{+}\right)$, $114.09\left(\mathrm{C}_{6} \mathrm{H}_{12} \mathrm{NO}^{+}\right)$, $128.11\left(\mathrm{C}_{6} \mathrm{H}_{12} \mathrm{~N}_{2} \mathrm{O}^{+}\right)$, and 146.08 $\left(\mathrm{C}_{6} \mathrm{H}_{12} \mathrm{NO}_{3}^{+}\right)$. The appearance of these heavy molecular

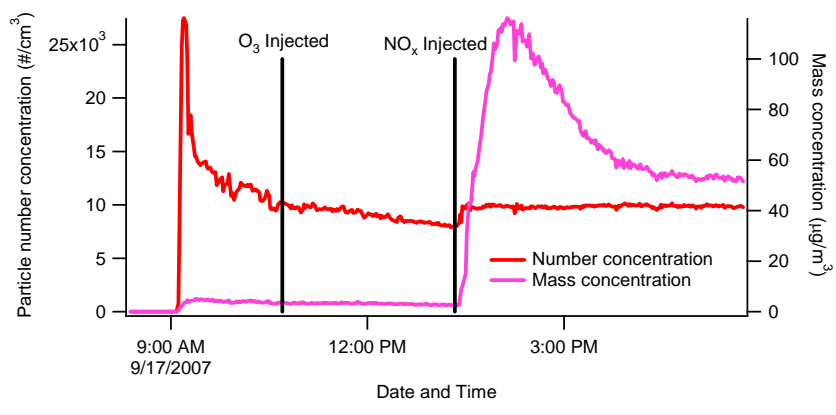

Fig. 8. Wall loss corrected aerosol mass and number evolution for propylamine $/ \mathrm{NO}_{3}$ reaction indicating a rapid and large increase in aerosol formation after addition of $\mathrm{NO}_{\mathrm{x}}$ followed by a rapid loss of a portion of this aerosol.
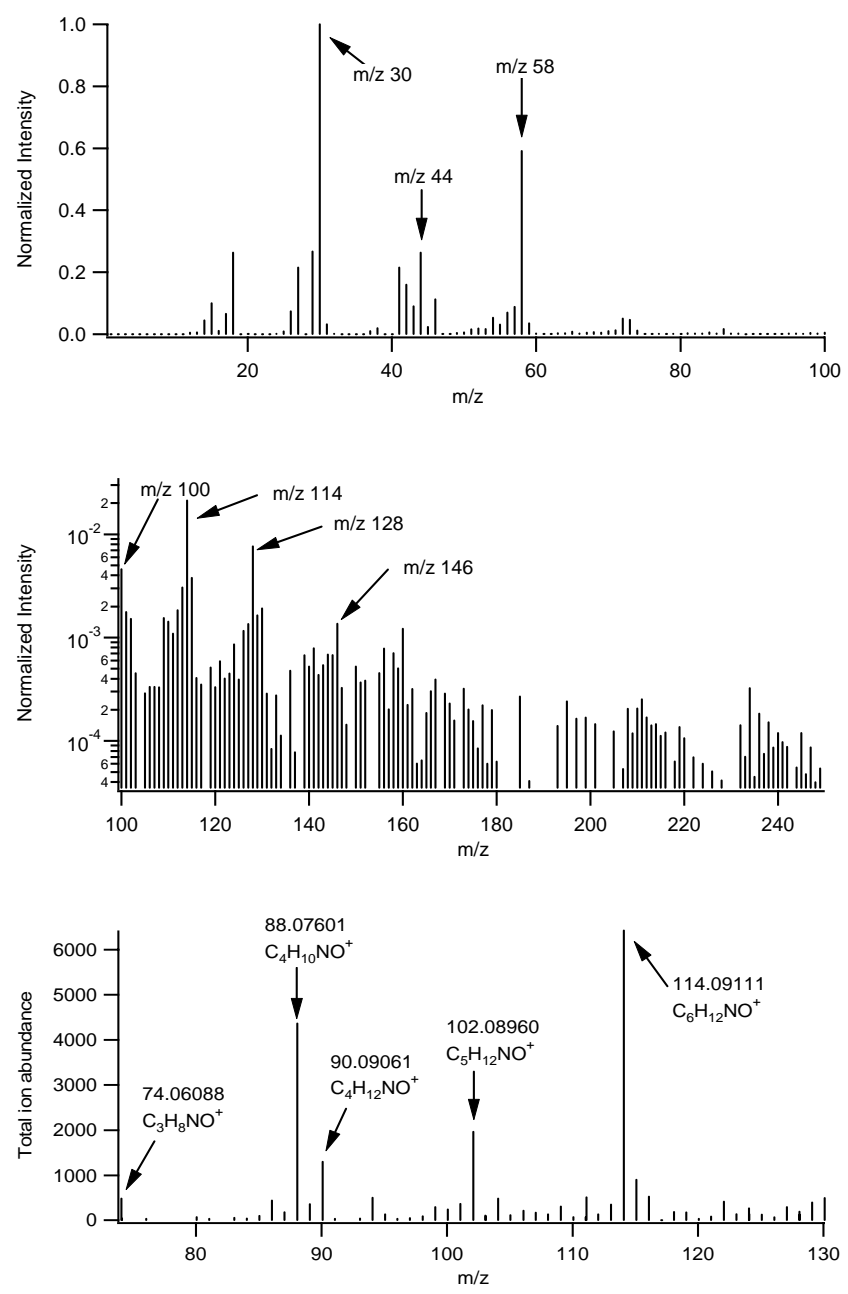

Fig. 9. Frames 1 and 2: AMS spectrum (normalized to $\mathrm{m} / \mathrm{z} 30$ ) of the propylamine/ $\mathrm{NO}_{3}$ system indicating presence of high mass fragments spaced 14 mass units apart. Frame 3: HPLC-TOF filter spectrum showing imine products and stable intermediates. 


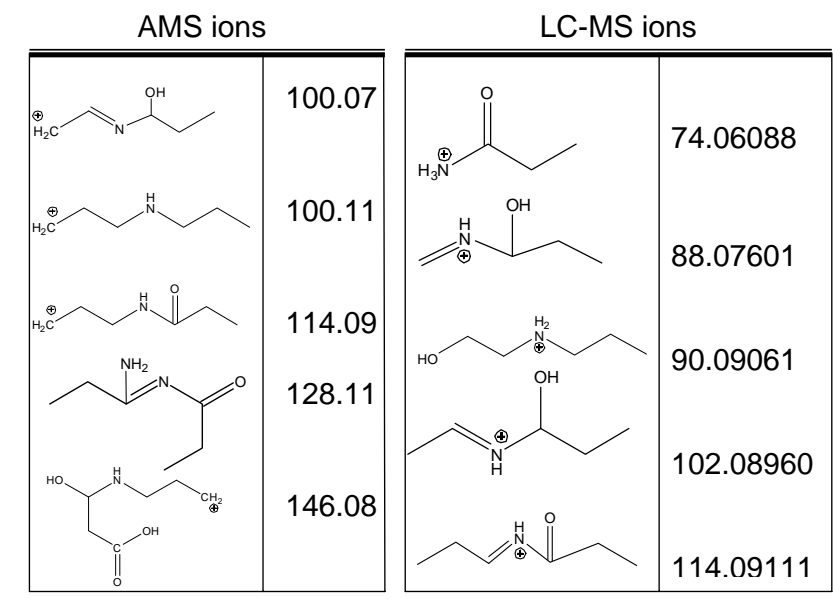

Fig. 10. Proposed structures of AMS and LC-MS ions for Propylamine/ $/ \mathrm{NO}_{3}$ system.

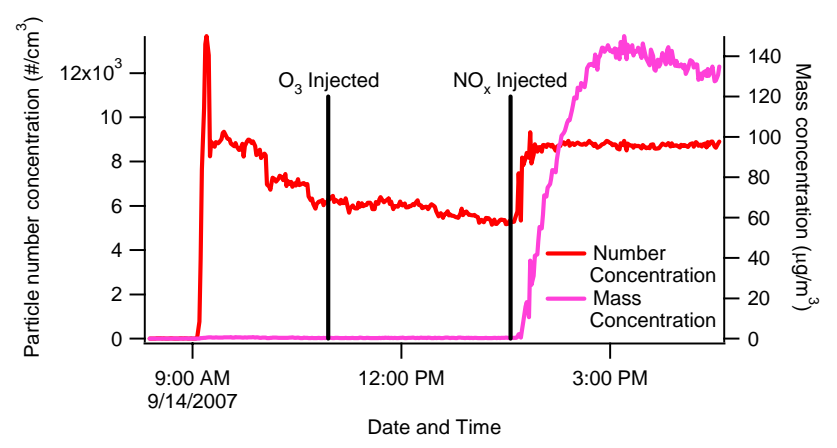

Fig. 11. Wall loss corrected aerosol mass and number evolution for butylamine $/ \mathrm{NO}_{3}$ reaction indicating a rapid and large increase in organic aerosol formation after addition of $\mathrm{NO}_{\mathrm{x}}$.

weight ions, some with no oxygen present, indicates the formation of nitrogen carbon bonds.

Mass spectra, normalized to the most abundant ion, obtained from the HPLC-TOF (Fig. 9) indicate several important ions. The 74.06088 peak can be attributed to the amide of propylamine. Also indicated in the HPLC-TOF spectra is the presence of ions with masses 88.07601, 90.09061, 102.08960, and 114.09111. These four ions have been identified as imines containing a hydroxyl group (88.07601$\mathrm{C}_{4} \mathrm{H}_{10} \mathrm{NO}^{+}$) and $\left(102.08960-\mathrm{C}_{5} \mathrm{H}_{12} \mathrm{NO}^{+}\right)$, a stable carbinolamine $\left(90.09061-\mathrm{C}_{4} \mathrm{H}_{12} \mathrm{NO}^{+}\right)$, and an imine containing a carbonyl group (114.0911- $\mathrm{C}_{6} \mathrm{H}_{12} \mathrm{NO}^{+}$). Figure 10 shows the major ions detected and their corresponding structure.

\subsection{Butylamine}

Not unlike the three previously examined amines, a large initial nucleation burst of aminium nitrate salt was observed after injection of butylamine into the chamber followed by a rapid decay in particle number. Addition of ozone resulted
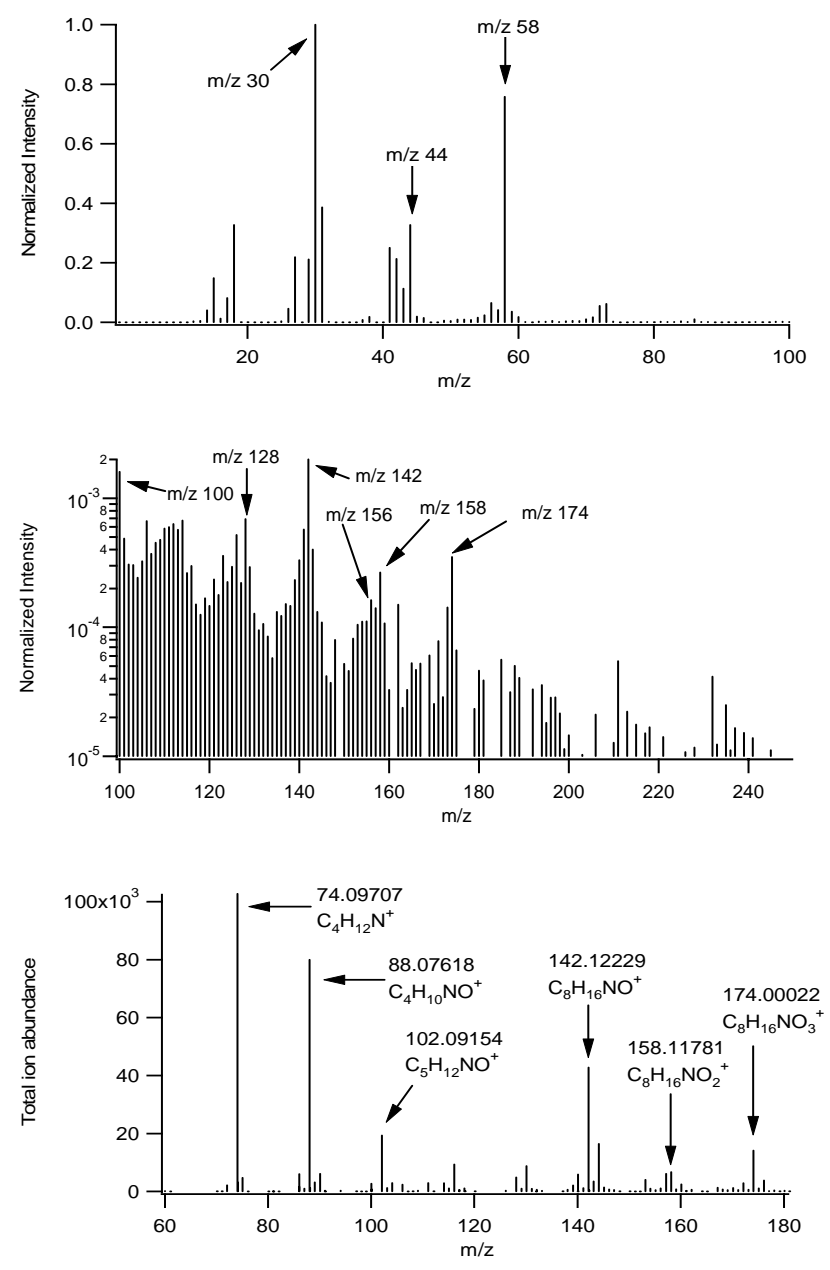

Fig. 12. Frames 1 and 2: AMS spectra normalized to largest peak $(\mathrm{m} / \mathrm{z}, 30)$ from butylamine/ $\mathrm{NO}_{3}$ system showing the formation of imines some with high degrees of oxidation. Frame 3. HPLC-TOF filter spectrum confirming presence of amide products.

in no obvious change in particle number or mass (Fig. 11). Only after addition of $\mathrm{NO}_{3}\left(\right.$ as $\left.\mathrm{O}_{3}+\mathrm{NO}\right)$ did we observe a rapid increase in particle mass and number, ultimately producing $130 \mu \mathrm{g} / \mathrm{m}^{3}$ (yield of 44\%).

Spectra from the AMS (Fig. 12) indicate high mass fragments much like the propylamine/ $/ \mathrm{NO}_{3}$ system. Employing the W-mode of the AMS we were able to identify these ions as $100.07\left(\mathrm{C}_{5} \mathrm{H}_{10} \mathrm{NO}^{+}\right), 128.10\left(\mathrm{C}_{7} \mathrm{H}_{14} \mathrm{NO}^{+}\right), 142.12$ $\left(\mathrm{C}_{8} \mathrm{H}_{16} \mathrm{NO}^{+}\right), 156.12\left(\mathrm{C}_{8} \mathrm{H}_{16} \mathrm{~N}_{2} \mathrm{O}^{+}\right) 158.11\left(\mathrm{C}_{8} \mathrm{H}_{16} \mathrm{NO}_{2}^{+}\right)$, and $174.11\left(\mathrm{C}_{8} \mathrm{H}_{16} \mathrm{NO}_{3}^{+}\right)$.

Figure 12 also shows the spectrum obtained from a filter sample. Again, many significant ions are observed in this spectrum including $102.09151\left(\mathrm{C}_{5} \mathrm{H}_{12} \mathrm{NO}^{+}\right), 142.12229$ $\left(\mathrm{C}_{8} \mathrm{H}_{16} \mathrm{NO}^{+}\right), \quad 158.11767\left(\mathrm{C}_{8} \mathrm{H}_{16} \mathrm{NO}_{2}^{+}\right)$, and 174.11122 $\left(\mathrm{C}_{8} \mathrm{H}_{16} \mathrm{NO}_{3}^{+}\right)$. Masses $74.09705\left(\mathrm{C}_{4} \mathrm{H}_{12} \mathrm{~N}^{+}\right)$and 88.07614 $\left(\mathrm{C}_{4} \mathrm{H}_{10} \mathrm{NO}^{+}\right)$represent the parent amine and amide formed during oxidation, while the ion appearing at 142.12229 


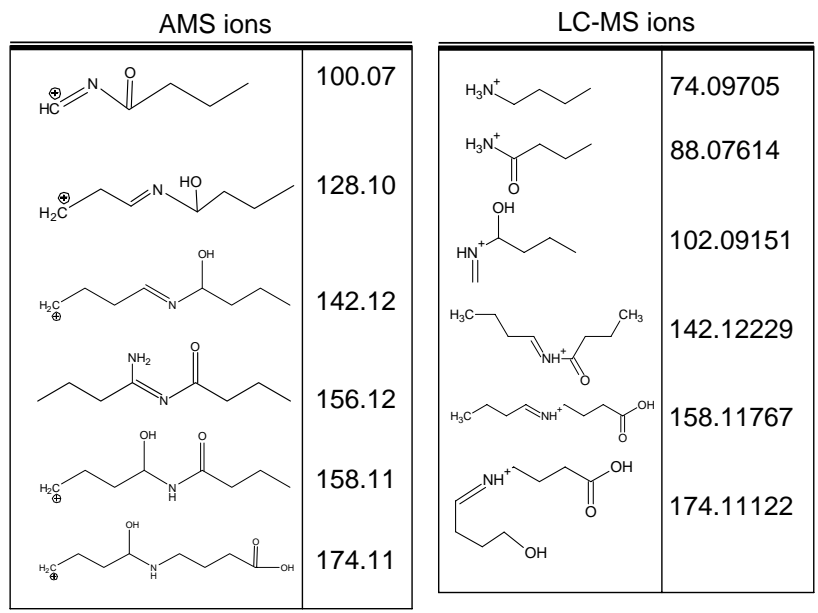

Fig. 13. Proposed structures of the AMS and LC-MS ions for Butylamine $/ \mathrm{NO}_{3}$ system.

corresponds to the formation of an imine product. Ions at 158 and 174 show among the highest degree of oxidation of any peaks observed, requiring the presence of 2 and 3 oxygen atoms respectively. Identification of a structure of these two peaks is difficult due to multiple possible empirical formulas. Major ions and their associated structures are shown in Fig. 13.

\section{Mass spectrum interpretation}

Two general trends are observed in the AMS and HPLC-TOF spectra: first, the formation of imines which contain a hydroxyl group (mass 88.07605 for ethylamine, mass 114.0911 for propylamine, and mass 142.12229 for butylamine); second, the presence of imines containing a carbonyl group (100.06 for ethylamine, 128.11 for propylamine, and 156.12 for butylamine). These peaks show extremely large carbon to oxygen ratios, allowing us to discount aldol condensation reactions as a route leading to their formation.

Furthermore, the observance of an amide peak in only those systems which formed aerosol (Fig. 14) indicates that it plays be a major role in the aerosol formation process. This is further supported from the high resolution HPLC-TOFMS, where the presence of the amide peak was confirmed for propylamine and butylamine (the ethylamine amide mass is below the $\mathrm{m} / \mathrm{z}$ capabilities of the HPLC-TOF). This observation is explained by examination of bond dissociation enthalpies (BDE) of the hydrogen attached to the alpha carbon of aliphatic amines (Lalevee et al., 2002). Lalevee noticed a decrease in energy as the alkyl chain increased in carbon number, thus indicating why methylamine, with a carbonhydrogen BDE of $92.4 \mathrm{kcal} / \mathrm{mol}$ was unable to oxidize to formamide, while ethyl, propyl, and butylamine with lower
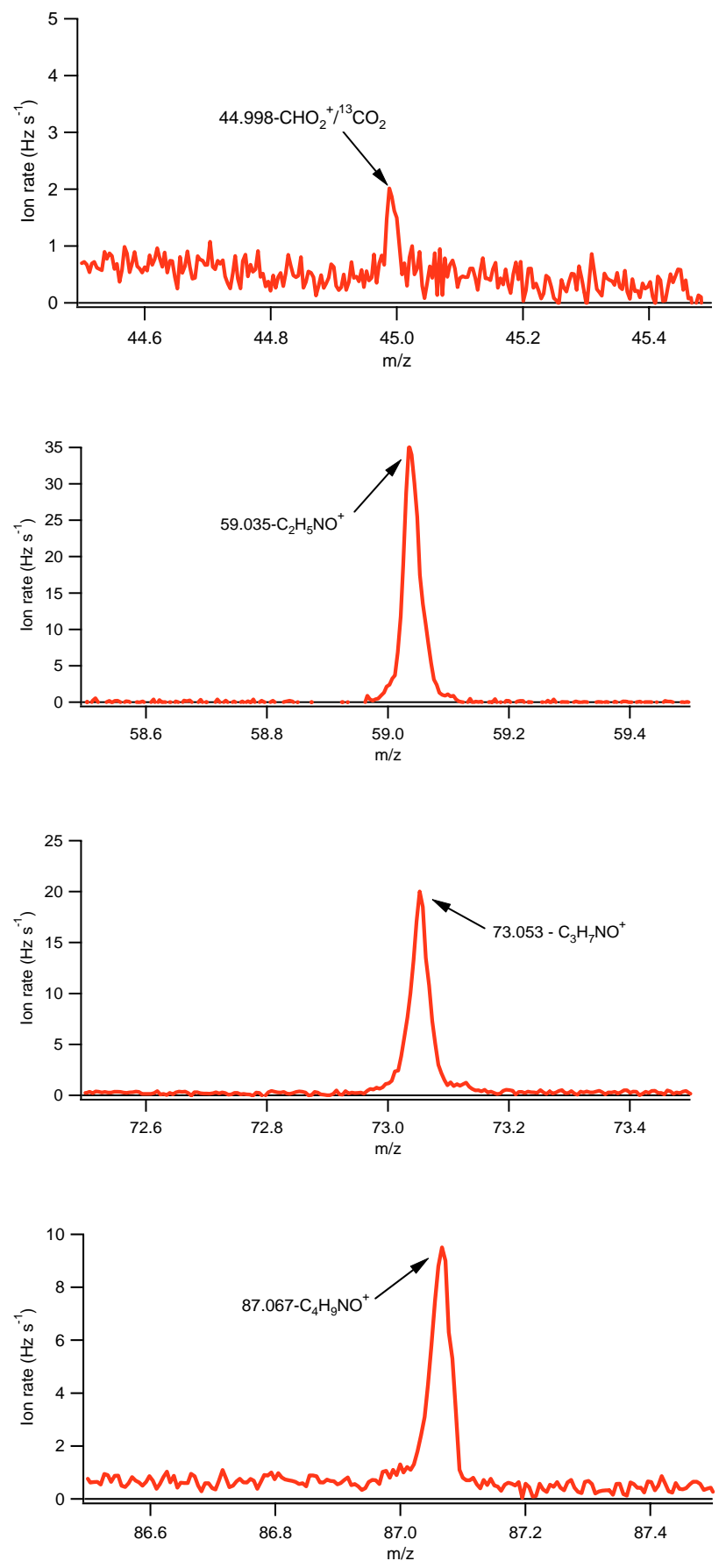

Fig. 14. Background subtracted W-mode spectrums of (from top to bottom) methylamine, ethylamine, propylamine, and butylamine systems indicating amide peaks are only present in the aerosol forming systems.

carbon-hydrogen BDE's were able to undergo hydrogen abstraction by $\mathrm{NO}_{3}$.

Finally, the observation of carbinolamines in ethyl, propyl, and butylamine systems suggests that the route of aerosol formation must include this class of compounds as an 


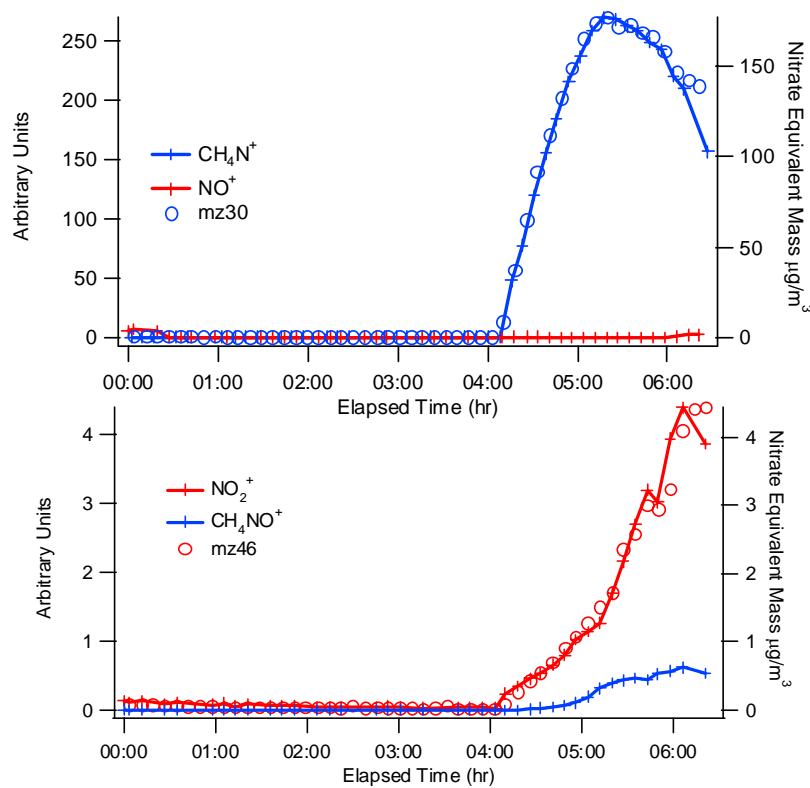

Fig. 15. Time traces of $m / z, 30$ ions (upper frame) and $m / z, 46$ ions (lower frame) plotted on the left Y-axis along with total mass formation of the respective ions (open circles), plotted on the right Y-axis for butylamine/ $\mathrm{NO}_{3}$. The absence of $\mathrm{NO}^{+}$and small amounts of $\mathrm{NO}_{2}^{+}$give further indication that aerosol formed was mostly organic in nature.

intermediate or product. The presence of carbinolamine compounds is not wholly unexpected as they are the intermediate compounds to imine formation via reactions between carbonyl compounds and primary or secondary amines. These compounds have been observed as intermediates in other carbonyl-amine reactions and have been shown to have a slow reverse reaction, remaining stable in solution for up to $24 \mathrm{~h}$ (Cheung et al., 2005; Cocivera et al., 1976; Pedersen et al., 1999).

\subsection{Salt formation and nitros/nitramines}

The particles formed immediately following injection of the amines followed the same trend of a rapid decrease in number concentration before eventually reaching an equilibrium concentration and is consistent with the particles achieving a gas-particle equilibrium. This same observation was made by Murphy et al. (2007) for a similar system who attributed it to the volatilization of Triethylaminium nitrate while undergoing gas-particle partitioning (Murphy et al., 2007). In all cases, with the exception of methylamine, the mass of particles formed during these events accounted for less than $4 \%$ of the total mass formed by the end of the experiment. In addition, $\mathrm{W}$-mode AMS data indicates the presence of strong $\mathrm{NO}^{+}$and $\mathrm{NO}_{2}^{+}$ions during this initial particle formation. The presence of strong $\mathrm{NO}^{+}$and $\mathrm{NO}_{2}^{+}$signals is a indication of aminium nitrate salt formation commonly ob-

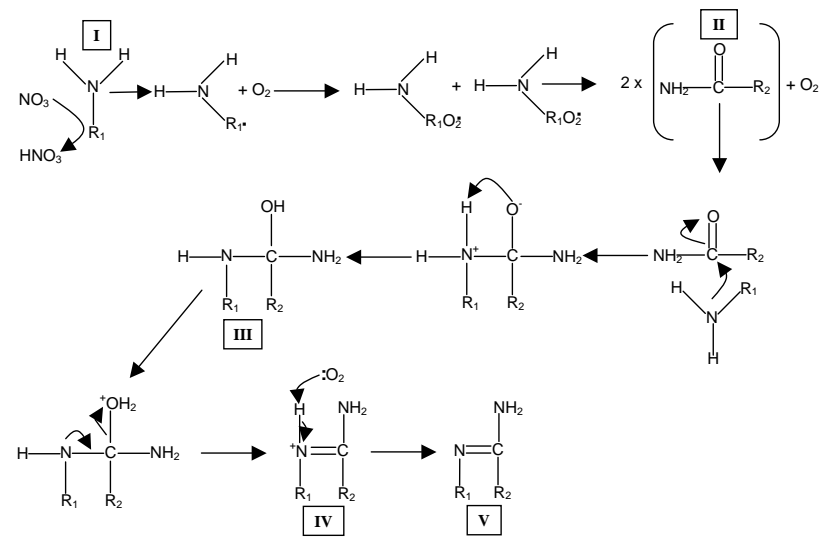

Fig. 16. Schematic of imine formation from a primary amine. $\mathrm{R}_{1}$ equals $\mathrm{CH}_{3}$ for methylamine, $\mathrm{C}_{2} \mathrm{H}_{5}$ for ethylamine, $\mathrm{C}_{3} \mathrm{H}_{7}$ for propylamine, etc. $\mathrm{R}_{2}$ equals $\mathrm{R}_{1}-\mathrm{CH}_{2}$ (i.e. $\mathrm{H}$ for methylamine, $\mathrm{CH}_{3}$ for ethylamine, $\mathrm{C}_{2} \mathrm{H}_{5}$ for propylamine, etc.).

served for acid-base reactions involving amines (Murphy et al., 2007; Fig. 4, panel B in Silva et al., 2008). However, we can exclude the corresponding aminium salts as a significant portion of the aerosol formed in the later portion of our experiments, after addition of $\mathrm{NO}_{3}$, due to the small contribution of $\mathrm{NO}^{+}$and $\mathrm{NO}_{2}^{+}$to the total aerosol signal (Fig. 15) during this period. Therefore, the complete lack of $\mathrm{NO}^{+}$signal and relatively small intensity of $\mathrm{NO}_{2}^{+}$signal during the later part of our experiments indicates that most of the secondary aerosol formed after addition of $\mathrm{NO}_{3}$ were not aminium nitrate salts and therefore must organic in nature.

Due to the extremely high vapor pressures associated with nitroamines and nitrosamines, their existence in the aerosol is highly unlikely. As evidence for this, the vapor pressure of N-nitros-butanamine and N-nitro-butanamine were calculated to be 24.3 and 1.4 torr respectively, using the group contribution method of Myrdal and Yalkowsky (1997). These two compounds were chosen because they are the highest molecular weight nitros/nitroamine compounds conceivably formed in our systems, and represent the most extreme cases. Additionally, the presence of nitroamines and nitrosamines can be excluded due to the absence of the expected strong molecular ions signal (Bulusu et al., 1970; Rainey et al., 1978). Other ions expected from the formation of these types of compounds would be a strong $\mathrm{NO}^{+}$ion associated with nitrosamines and $\mathrm{NO}_{2}^{+}$ions from nitroamines, neither of which were observed in significant amounts in AMS spectra as stated earlier. While the possible decomposition of these compounds cannot be definitively ruled out, due to their high vapor pressures, it is highly unlikely they are capable of being present in the aerosol in appreciable amounts. 


\section{Proposed aerosol formation mechanism}

We propose a reaction sequence (Fig. 16) similar to that of formation of a Schiff base. Mass spectral evidence of amide formation, coupled with the observation of the carbinolamine intermediate and imine product in only those systems that formed aerosol gives support to this proposed mechanism. In this reaction, the amine (compound I in Fig. 16) reacts with the nitrate radical, losing a hydrogen attached to the alpha carbon leading to formation of a peroxy radical. This peroxy radical, in the absence of $\mathrm{NO}$, can undergo $\mathrm{RO}_{2}$ $\mathrm{RO}_{2}$ self reactions yielding 2 amide molecules (compound II) and molecular oxygen. Alternatively, amide products may be generated by reactions between $\mathrm{RO}_{2}$ and $\mathrm{NO}_{3}$ leading to $\mathrm{NO}_{2}$ and $\mathrm{O}_{2}$ byproducts. Subsequent reactions between the amide molecule and the parent amine proceeds by a nucleophilic attack by the parent amine on an amide, followed by a 1,3-hydrogen transfer forming a stable carbinolamine intermediate (compound III). Compounds II and III have been confirmed by mass spectral analysis as present in our aerosol in all three aerosol forming systems. The hydroxyl group of the carbinolamine will then undergo protonation followed by dehydration resulting in formation of an iminium ion (compound IV). Loss of the hydrogen from the positively charged nitrogen ultimately leads to formation of an imine (compound $\mathrm{V}$ ). The imine product (compound $\mathrm{V}$ ) has also been observed in all three aerosol forming systems by means of online and offline mass spectra techniques.

Imine formation has been observed on particle surfaces, and is known to be promoted in slightly acidic conditions (pH 4-5) (Haddrell and Agnes, 2004; Zahardis et al., 2008; Jencks, 1959). However, without structural information, the assignments of mass spectrum ions remain tentative and can only be extended to empirical formula confirmation. Therefore, other reaction mechanisms cannot be completely ruled out.

To confirm the particle formation resulted from oxidation by $\mathrm{NO}_{3}$, additional experiments under dark conditions with only the parent amine and $\mathrm{N}_{2} \mathrm{O}_{5}$ present were performed. These results indicated no significant mass formation until injection of $\mathrm{N}_{2} \mathrm{O}_{5}$, which subsequently resulted in a rapid burst of particle number and volume, identical to the experimental results shown above.

\section{Implications}

The data presented here indicates that under nighttime conditions, in locations with sufficiently high nitrate radical concentrations, reactions of primary amines with the nitrate radical can be of great importance to new particle formation. We observe that the formation of organic aerosol from reactions between primary amines and $\mathrm{NO}_{3}$ is sufficiently fast to be competitive with the acid-base reactions leading to aminium nitrate salts production. This was supported by online and offline mass spectrometry which showed organic aerosol formation dominating the aerosol mass spectra. Aerosol mass yields for the four amines studied were estimated to be $<2 \%$ for methylamine, $23 \%$ for propylamine, while ethylamine and butylamine had yields of $\sim 44 \%$.

The presence of amide products in all three aerosol forming systems indicate that the C-H bond strengths for ethyl, propyl, and butylamine were sufficiently weak to be abstracted by $\mathrm{NO}_{3}$, while methylamine oxidation by nitrate did not produce observable amide products. Observation of carbinolamine and imine products demonstrated that the oxidation of primary aliphatic amines proceeds by a Schiff base reaction mechanism, ultimately leading to imine formation. This implies that secondary oxidation chemistry plays a key role in the new particle formation processes from amines. Furthermore, these experiments suggest that further research into the reaction kinetics of nitrate and amines is needed, as there is no data in the current literature providing kinetic measurements. As such, aerosol formation from amines may be greatly under predicted by current air quality models and more research is needed in order to understand the complex interactions of amines and $\mathrm{NO}_{3}$ in the lower troposphere.

Acknowledgements. The author would like to thank Kurt Bumiller, Chuck Buffalino, Lindsay D. Yee, Christina Zapata, Rebecca Austin, Dylan Switzer and Clayton Stothers for experimental setup and support. Funding for this work was provided by National Science Foundation Grants ATM-0449778 and ATM0735396, W. M. Keck Foundation, and the University of California Transportation Research Center.

Edited by: J. Thornton

\section{References}

Angelino, S., Suess, D. T., and Prather, K. A.: Formation of aerosol particles from reactions of secondary and tertiary alkylamines: Characterization by aerosol time-of-flight mass spectrometry, Environ. Sci. Technol., 35, 3130-3138, 2001.

Bailey, D., Cativiela, J. P., Descary, B., Grantz, D., Hamilton, K. D., Martin, P. E., Meyer, D., Mullinax, D., Simunovic, C. A., Sweet, J., Warner, D., and Watson, J.: Dairy Emissions Factors for Volatile Organic Compounds, San Joaquin Valley Air Pollution Control District, Fresno, CA, 2005.

Barsanti, K. C., McMurry, P. H., and Smith, J. N.: The potential contribution of organic salts to new particle growth, Atmos. Chem. Phys. Discuss., 8, 20723-20748, 2008, http://www.atmos-chem-phys-discuss.net/8/20723/2008/.

Beddows, D. C. S., Donovan, R. J., Harrison, R. M., Heal, M. R., Kinnersley, R. P., King, M. D., Nicholson, D. H., and Thompson, K. C.: Correlations in the chemical composition of rural background atmospheric aerosol in the UK determined in real time using time-of-flight mass spectrometry, J. Environ. Monitor., 6, 124-133, 2004.

Bowman, F. M., Odum, J. R., Seinfeld, J. H., and Pandis, S. N.: Mathematical model for gas-particle partitioning of secondary organic aerosols, Atmos. Environ., 31, 3921-3931, 1997. 
Carter, W. P. L., Cocker, D. R., Fitz, D. R., Malkina, I. L., Bumiller, K., Sauer, C. G., Pisano, J. T., Bufalino, C., and Song, C.: A new environmental chamber for evaluation of gas-phase chemical mechanisms and secondary aerosol formation, Atmos. Environ., 39, 7768-7788, 2005.

Cheung, A., Struble, E., He, J. Y., Yang, C., Wang, E., Thurston, D. E., and Liu, P.: Direct liquid chromatography determination of the reactive imine SJG-136 (NSC 694501), J. Chromatogr. B, 822, 10-20, 2005.

Cocivera, M., Fyfe, C. A., Effio, A., Vaish, S. P., and Chen, H. E.: Flow Nuclear Magnetic-Resonance Study of Dehydration of Tetrahedral Intermediate Resulting from Addition of Hydroxylamine to Acetaldehyde, J. Am. Chem. Soc., 98, 1573-1578, 1976.

DeCarlo, P. F., Kimmel, J. R., Trimborn, A., Northway, M. J., Jayne, J. T., Aiken, A. C., Gonin, M., Fuhrer, K., Horvath, T., Docherty, K. S., Worsnop, D. R., and Jimenez, J. L.: Field-deployable, high-resolution, time-of-flight aerosol mass spectrometer, Anal. Chem., 78, 8281-8289, 2006.

Finlayson-Pitts, B. and Pitts, J. N.: Chemistry of the Upper and Lower Atmosphere, Academic Press, 2000.

Glagolenko, S. and Phares, D. J.: Single-particle analysis of ultrafine aerosol in College Station, Texas, J. Geophys. Res.-Atmos., 109, D18205, doi:10.1029/2004JD004621, 2004.

Haddrell, A. E. and Agnes, G. R.: A class of heterogeneous/multiphase organic reactions studied on droplets/particles levitated in a laboratory environment: aldehyde plus 1,8diaminonaphthalene equals imine, Atmos. Environ., 38, 545556, 2004.

Jencks, W. P.: Studies on the Mechanism of Oxime and Semicarbazone Formation, J. Am. Chem. Soc., 81, 475-481, 1959.

Lalevee, J., Allonas, X., and Fouassier, J. P.: N-H and alpha(C-H) bond dissociation enthalpies of aliphatic amines, J. Am. Chem. Soc., 124, 9613-9621, 2002.

Manahan, S. E.: Environmental Chemistry, 4th Ed., Lewis, 1990.

Murphy, D. M. and Thomson, D. S.: Chemical composition of single aerosol particles at Idaho Hill: Positive ion measurements, J. Geophys. Res.-Atmos., 102, 6341-6352, 1997

Murphy, S. M., Sorooshian, A., Kroll, J. H., Ng, N. L., Chhabra, P., Tong, C., Surratt, J. D., Knipping, E., Flagan, R. C., and Seinfeld, J. H.: Secondary aerosol formation from atmospheric reactions of aliphatic amines, Atmos. Chem. Phys., 7, 2313-2337, 2007, http://www.atmos-chem-phys.net/7/2313/2007/.

Myrdal, P. B. and Yalkowsky, S. H.: Estimating pure component vapor pressures of complex organic molecules, Ind. Eng. Chem. Res., 36, 2494-2499, 1997.
Odum, J. R., Hoffmann, T., Bowman, F., Collins, D., Flagan, R. C., and Seinfeld, J. H.: Gas/particle partitioning and secondary organic aerosol yields, Environ. Sci. Technol., 30, 2580-2585, 1996.

Pedersen, E. J., Urbansky, E. T., Marinas, B. J., and Margerum, D. W.: Formation of cyanogen chloride from the reaction of monochloramine with formaldehyde, Environ. Sci. Technol., 33, 4239-4249, 1999.

Pitts, J. N., Grosjean, D., Vancauwenberghe, K., Schmid, J. P., and Fitz, D. R.: Photo-Oxidation of Aliphatic-Amines under Simulated Atmospheric Conditions - Formation of Nitrosamines, Nitramines, Amides, and Photo-Chemical Oxidant, Environ. Sci. Technol., 12, 946-953, 1978.

Schade, G. W. and Crutzen, P. J.: Emission of Aliphatic-Amines from Animal Husbandry and Their Reactions - Potential Source of $\mathrm{N}_{2} \mathrm{O}$ and HCN, J. Atmos. Chem., 22, 319-346, 1995.

Seinfeld, J. H. and Pandis, S. N.: Atmospheric Chemistry and Physics: From Air pollution to Climate Change, John Wiley and Sons, Inc., 1998.

Silva, P., Erupe, M., Malloy, Q. G. J., Li, Q., Warren, B., Price, D., Elias, J., and Cocker, D. R.: Trimethylamine as Precursor to Secondary Organic Aerosol Formation via Nitrate Radical Reaction in the Atmosphere, Environ. Sci. Technol., 42, 4689-4696, 2008.

Smith, J. N., Dunn, M. J., VanReken, T. M., Iida, K., Stolzenberg, M. R., McMurry, P. H., and Huey, L. G.: Chemical Composition of Atmospheric Nanoparticles Formed from Nucleation in Tecamac, Mexico: Evidence for an Important Role of Organic Species in Nanoparticle Growth, Geophys. Res. Lett., 35, L04808, doi:10.1029/2007GL032523, 2008.

Tan, P. V., Evans, G. J., Tsai, J., Owega, S., Fila, M. S., and Malpica, O.: On-line analysis of urban particulate matter focusing on elevated wintertime aerosol concentrations, Environ. Sci. Technol., 36, 3512-3518, 2002.

Wang, S. C. and Flagan, R. C.: Scanning Electrical Mobility Spectrometer, Aerosol Sci. Tech., 13, 230-240, 1990.

Westerholm, R., Li, H., and Almen, J.: Estimation of Aliphatic Amine Emissions in Automobile Exhausts, Chemosphere, 27, 1381-1384, 1993.

Zahardis, J., Geddes, S., and Petrucci, G. A.: The ozonolysis of primary aliphatic amines in fine particles, Atmos. Chem. Phys., 8, 1181-1194, 2008, http://www.atmos-chem-phys.net/8/1181/2008/. 